\title{
Review of 'The provision of services for the prenatal diagnosis of fetal abnormality in the United Kingdom'. Report of the Clinical Genetics Society Working Party. Supplement No 3 to the Bulletin of the Eugenics Society, November 1978
}

The rapid growth of methods to diagnose fetal disease in early pregnancy has left many clinicians bewildered and confused. For this reason the Council of the Clinical Genetics Society set up a working party in 1976 to consider the facilities available in the UK and the present demand for these services. The working party was also to make recommendations for the future, particularly on the need for a national register. The ten members of the (all male) working party, under the chairmanship of Professor M A Ferguson-Smith, met five times in the year up to December 1977 and produced a unanimous report which was published in November 1978. There is considerable advantage in considering the report over a year later, since it can be viewed in perspective with particular note of the changed political climate. The year 1979 saw the election of a Conservative government committed to reducing public expenditure, the onset of a world recession which is a major blow to many research institutions, and progress in parliament of Mr John Corrie's bill to amend the Abortion Act of 1967.

Against these powerful political forces the report details a mass of data on the UK rate of fetal abnormality, the numbers detected (or detectable or both) by prenatal diagnosis, regional variation throughout the country, and the results of retrospective monitoring of prenatal diagnosis up to the end of 1976. Not surprisingly, the working party found that in 1976 less than $10 \%$ of 'at risk' pregnancies were tested by amniocentesis (and appropriate cell culture or biochemical techniques), that the available resources were grossly inadequate, and that quality control was also unsatisfactory especially as regards monitoring pregnancy outcome after amniocentesis. The report makes six detailed recommendations, particularly that the "current makeshift arrangements" be replaced by the creation of a Standing Committee on Genetic Services and a National Register of Amniocentesis (for Prenatal Diagnosis). The report also recommends a national programme of maternal serum AFP screening, continued collaboration between research centres in
Great Britain and other European countries, and, meantime, the making available of amniocentesis and prenatal diagnostic services sufficient for $8 \%$ of all pregnancies.

These recomendations were warmly welcomed by and appeared most reasonable to those already immersed in medical genetics, but they provoke different responses in politicians, economists, and health board administrators. Above all, will public demand for adequate prenatal diagnostic services be strong enough to withstand the counterarguments that the services are too expensive and must take second place to other health and social innovations? Do the women who have been subjected to amniocentesis give unqualified support to an extension of the service? With these issues in mind, a severe criticism of the working party report is that it concentrates on the technology of prenatal diagnosis, ultrasound control, amniocentesis, and well staffed laboratories. Having noted the lack of genetic counselling facilities, the report (page 17) states that ". . . the genetic consultation will have to be reserved for special cases. A 15 to 20 minute consultation is in general sufficient to give the patient and her husband full information ...". If a few women had been on the working party, this aspect of the report would surely have been different.

The major problem in medicine today is that doctors have not yet discovered that their patients are increasingly articulate, have a greater background knowledge than ever before, and can, if given the relevant facts for their situation, make thoughtful and wise decisions. The preventive aspect of medical genetics rests firmly on this thesis. It will be extremely sad if the excellent ground work and all the data collated by the working party were to be wasted because they underestimated the extent to which prenatal diagnostic provisions are a political decision and that such decisions depend not on technology but on people.

JOHN A RAEBURN Department of Human Genetics, Western General Hospital, Edinburgh EH4 $2 X U$. 